\title{
Medication Lost
}

National Cancer Institute

\section{Source}

National Cancer Institute. Medication Lost. NCI Thesaurus. Code C102663.

The medication is no longer held or possessed by the subject and is incapable of being recovered or regained. 